\title{
DNA methylation-mediated caspase-8 downregulation is associated with anti-apoptotic activity and human malignant glioma grade
}

\author{
YUEQIU TENG ${ }^{1,2}$, YU-CUI DONG ${ }^{1}, \mathrm{ZHAOYU} \mathrm{LIU}^{1}, \mathrm{YAN} \mathrm{ZOU}^{1}, \mathrm{HUI} \mathrm{XIE}^{1}, \mathrm{YU}^{\mathrm{Z}} \mathrm{ZHAO}{ }^{1}$, \\ JUN SU ${ }^{3}$, FENGLIN CAO ${ }^{2}$, HUA JIN ${ }^{3}$ and HUAN REN ${ }^{1}$ \\ ${ }^{1}$ Department of Immunology, Harbin Medical University, Harbin, Heilongjiang 150081; ${ }^{2}$ Central Laboratory of Blood Cancer, \\ The First Affiliated Hospital of Harbin Medical University, Harbin, Heilongjiang 150001; ${ }^{3}$ Department of Neurosurgery, \\ The Third Affiliated Hospital of Harbin Medical University, Harbin, Heilongjiang 150040, P.R. China
}

Received January 24, 2016; Accepted January 27, 2017

DOI: $10.3892 / \mathrm{ijmm} .2017 .2881$

\begin{abstract}
The methylation-mediated silencing of tumor suppressors, including key apoptosis-related genes plays an important role in the pathogenesis and therapeutic resistance in human cancer. In this study, we aimed to elucidate the role and mechanisms of resistance to apoptosis with caspase- 8 gene downregulation in human malignant glioma. Reverse transcription-polymerase chain reaction (RT-PCR) and methylation-specific PCR (MSP) were used to examine caspase-8 expressoin at the mRNA level and gene methylation status in normal brain tissue, glioma tissue and cancer cell lines. Caspase- 8 protein kinase activity was measured by caspase- 8 colorimetric assays; cell apoptosis was examined by Annexin V/ propidium iodide (PI) staining; the rates of tumor cell apoptosis were detected by flow cytometry. Our results revealed that caspase- 8 gene silencing may result from the methylation of its gene promoter in human glioma tissues. The expression of caspase- 8 at the mRNA level was significantly associated with the grade of human glioma. In certain human cancer cell lines, the expression at the mRNA level, protein kinase activity and tumor cell anti-apoptotic activity and resistance were related to the methylation status of the caspase- 8 gene promoter. Thus, the caspase- 8 gene methylation status may be used as an indicator for the early diagnosis of human malignant glioma. Combination therapy with demethylation reagents may overcome therapeutic resistance in the same malignancy.
\end{abstract}

Correspondence to: Professor Huan Ren, Department of Immunology, Harbin Medical University, 157 Baojian Road, Harbin, Heilongjiang 150081, P.R. China

E-mail: huanren2009@126.com; renhuan@ems.hrbmu.edu.cn

Dr Hua Jin, Department of Neurosurgery, The Third Affiliated Hospital of Harbin Medical University, 150 Haping Road, Harbin, Heilongjiang 150040, China

E-mail: hydsjwk@163.com

Key words: caspase-8, glioma, DNA methylation, gene silencing, anti-apoptosis

\section{Introduction}

Malignant glioma is the most common primary brain tumor affecting adults and is graded according to the World Health Organization (WHO) 2007 pathological classifications as follows: grade I, pilocytic astrocytoma is generally benign; grade II, low-grade astrocytoma (LGA); grade III, anaplastic astrocytoma (AA) is prone to transformation into grade IV; and grade IV, glioblastoma (GBM) (1). Malignant astrocytoma (MA) mainly includes AA and GBM, of which the latter, accounts for $50-80 \%$ of all MA cases. The median survival of patients with GBM is approximately 12-15 months despite current therapeutic strategies.

Uncontrolled cell apoptosis is one of the most important mechanisms for tumor pathogenesis and thereof therapeutic resistance (2-5). The caspase family is involved in the initiation of early apoptosis, signal transduction and later stage apoptotic effects. One of the key members is caspase-8, an apoptosis initiation factor which is closely related to the occurrence and development of cancer (6). In the extrinsic death receptormediated type I apoptotic pathway, Fas ligand and tumor necrosis factor bind to the death receptors, which subsequently interact with the adaptor protein, Fas-associated protein with death domain (FADD) and pro-caspase-8, forming the deathinducing signaling complex (DISC). Caspase- 8 activation in the DISC leads to cleavage of pro-caspase- 3 and caspase- 3 activation $(7,8)$. In the intrinsic mitochondrial-associated type II apoptotic pathway, pro-caspase-9 is activated by cytochrome $c$, and Smac is released from the damaged mitochondria. Pro-caspase-9 activation leads to the activation of key apoptotic effectors, including caspase-3. Pro-caspase- 8 activation can also cleave Bid to trigger mitochondrial cytochrome $c$ release for caspase-3 activation (9). Thus, caspase-3 activation is identified as the key biomarker of the apoptotic pathway in the irreversible stage (10).

In cancer cells, the aberrant methylation of $\mathrm{CpG}$ islands located in the promoter regions of genes that are implicated in cell apoptosis, tumor cell migration, or DNA repair process is frequently associated with transcriptional silencing or repression, particularly in the tumor suppressor genes (11-14). For 
example, the methylation of $\mathrm{P}^{1} 6^{\mathrm{INK} 4}$ is widespread in multiple myeloma (15). Sun et al (16) found that the methylation of the caspase- 8 gene increased tumor susceptibility in many types of cancer, including lung, esophageal, gastric, colorectal and breast cancer. In sporadic colorectal cancers, the methylation status of $\mathrm{O}^{6}$-methylguanine-DNA-methyltransferase (MGMT) differs among tumor tissue, para-carcinoma tissue and normal tissue, implying that specific gene defects resulting from MGMT epigenetic loss are associated with colorectal cancer development (17). The aberrant methylation of the p33 ${ }^{\text {ING1b }}$ gene, and in parallel, significantly reduced or absent mRNA levels of the gene have been detected in ovarian cancer samples (18). Moreover, alterations of the 'epigenome' may contribute to biological behaviors and classifications of human cancer (14). For example, the methylation rates of the death-associated protein kinase (DAPK), MGMT and Ras-association domain family 1, isoform A (RASSF1A) genes have been shown to be significantly higher in highgrade cervical squamous cell carcinomas (19). Aberrant DNA methylation is involved in clear cell renal carcinoma invasion and metastasis (20), and affects the survival time of patients with gastric cancer (21).

Nevertheless, the link between the aberrant gene expression of anti-apoptotsc effectors, i.e., the caspase family members, and the pathogenesis of human malignant glioma remains unclear. In this study, we assessed caspase- 8 gene expression levels and methylation status in human normal brain, glioma tissue and cancer cell lines, and found that downregulated capase- 8 levels were significantly associated with the grade of malignant glioma. Moreover, we verified an association between the capase- 8 methylation-related gene downregulation and an enhanced anti-apoptotic activity in selected human cancer cells. Our data thus suggest that caspase- 8 gene methylation may serve as an indicator for the early diagnosis of human malignant glioma. Combination therapy with demethylation reagents may overcome resistance in the same malignancy.

\section{Materials and methods}

Human glioma tissue specimens and cancer cell lines. From August, 2010 to December, 2012, 66 glioma tissue samples were obtained from patients who underwent resection of cerebral gliomas. Normal brain tissue samples were obtained from 5 patients with brain trauma. This study was approved by the Institutional Research Board of Harbin Medical University and a signed consent form was obtained from each patient prior to obtaining the samples. Histopathological examination revealed that of the 66 patients, 15 had pilocytic astrocytoma, 8 had oligodendroglioma, 13 had anaplastic oligoastrocytoma and 30 had glioblastoma. According to the WHO classification of tumors of the central nervous system (1), our cases were graded as follows: 23 cases belonged to the grade I-II low-level group and 43 cases belonged to the grade III-IV high-level group. Of the 66 cases, 35 were males and 31 were females. The age of the patients ranged from 5 to 65 years (mean age, $36.7 \pm 15.2$ years). None of the cancer patients had received radiotherapy or chemotherapy prior to surgery (Table I). Furthermore, another set of 10 human glioblastoma (WHO grade IV) patient tissue samples were collected at the same hospital and were randomly selected for further analysis. The same patient selection and diagnosis criteria, as well as the informed consent form, were applied to this set of specimens. All specimens confirmed by neuropathological diagnosis were stored at $-80^{\circ} \mathrm{C}$ after freezing in liquid nitrogen.

In the present study, we used various human cancer cell lines (originally obtained from ATCC and maintained in our laboratory) as follows: the U87MG, RG, T98, LN229, LN18 and U343 glioma cell lines; the HT29, LoVo, HCT116, SW620 and SW1116 colorectal cancer cell lines; the DU145 and PC3 prostate cancer cell lines; the HeLa cervical caner cells; the A431 human epidermoid carcinoma cells; and the K562 leukemia cells. The cells were grown in Dulbecco's modified Eagle's medium (DMEM) containing 10\% fetal bovine serum (FBS). All cell lines were cultured in an atmosphere of $5 \% \mathrm{CO}_{2}$ at $37^{\circ} \mathrm{C}$.

Extraction of total RNA, cDNA synthesis and reverse transcription-PCR. TRIzol reagent (Invitrogen, Carlsbad, USA) was used to extract total RNA from the tissues and cell lines. SuperScript II transcription enzyme, oligonucleotide(dT), and random primers (high capactiy cDNA reverse transcription kit; Applied Biosystems) were incubated with total RNA for reverse transcription. The entire process was carried out in accordance with the manufacturer's instructions. The synthesized cDNA was stored at $-70^{\circ} \mathrm{C}$. The primers used to amplify the caspase- 8 gene and the internal reference genes, glyceraldehyde-phosphate dehydrogenase (GAPDH) in tissues and $\beta$-actin in cell lines, are listed in Table II. The size of the amplified fragments for caspase-8, GAPDH and $\beta$-actin were 427, 240 and $336 \mathrm{bp}$, respectively. The $50 \mu 1 \mathrm{PCR}$ reaction included $1 \mathrm{X}$ buffer, $1.5 \mathrm{mM}$ $\mathrm{MgCl}_{2}, 10$ pmol bidirectional primers, $0.2 \mathrm{mM}$ deoxynucleoside triphosphates (dNTPs), 1 unit TaqDNA polymerase, cDNA and double-distilled water. A PCR reaction without a template was used as the negative control. The PCR reaction conditions were as follows: denaturation at $94^{\circ} \mathrm{C}$ for $5 \mathrm{~min}$; denaturation at $94^{\circ} \mathrm{C}$ for $30 \mathrm{sec}$, annealing at $60^{\circ} \mathrm{C}$ for $45 \mathrm{sec}$, extension at $72^{\circ} \mathrm{C}$ for $45 \mathrm{sec}, 28$ cycles; extension at $72^{\circ} \mathrm{C}$ for $10 \mathrm{~min}$. PCR products were separated on a $1.2 \%$ agarose gel (with ethidium bromide staining). The resultant gel image was analyzed using the AlphaImager gel analysis system. Each analysis was repeated 3 times, and the mean was obtained in order to reduce error. The level of caspase- 8 mRNA expression in the glioma and normal brain tissues was determined by semi-quantitative RT-PCR. The semi-quantitative value was expressed as an integrated optical density ratio (irOD), where irOD = (average caspase- 8 electrophoresis optical density $\mathrm{x}$ area)/(average GAPDH electrophoresis optical density $x$ area). A ratio of $>0.5$ was considered as positive expression, and a ratio of $\leq 0.5$ was considered as negative expression.

Extraction of DNA. The Qiagen DNeasy kit (Qiagen Co. Ltd., Shanghai, China) was used to extract DNA from the tissues and cell lines. Extracted DNA was first subjected to agarose gel electrophoresis to detect whether there was any degradation. Subsequently, the quality and quantity of the extracted DNA was determined using an ultraviolet (UV) spectrophotometer (BioPhotometer plus; Eppendorf Co., Ltd., Hamburg, Germany). An OD value of 260/280 nm between 1.8 and 2.0 was used as the quality standard. 
Table I. Association between the expression of caspase- 8 and clinicopathological characteristics in patients with human glioma $(n=66)$.

\begin{tabular}{lllll}
\hline & & \multicolumn{2}{c}{ Expression of caspase-8 } \\
\cline { 3 - 5 } Characteristic & No. & Negative & Positive & P-value \\
\hline Age & & & & \\
$<40$ & 30 & 25 & 5 & $>0.05$ \\
$\geq 40$ & 36 & 29 & 7 & \\
Gender & & & & \\
Male & 35 & 27 & 8 & $>0.05$ \\
Female & 31 & 27 & 4 & \\
Tumor volume & & & & \\
$<25 \mathrm{~cm}^{3}$ & 30 & 24 & 6 & $>0.05$ \\
$\geq 25 \mathrm{~cm}^{3}$ & 36 & 30 & 6 & \\
Tumor grade & & & & \\
I-II & 23 & 15 & 8 & $<0.05$ \\
III-IV & 43 & 39 & 4 & \\
\hline
\end{tabular}

Bisulfite modification. As per the reported literature (22), bisulfite modification was performed as follows. First, $2 \mu \mathrm{g}$ of DNA were diluted with $25 \mathrm{ml}$ distilled water and heated for 5 min in a water bath maintained at $95^{\circ} \mathrm{C}$. The denaturation DNA was then mixed with $2 \%$ low-melting-point agarose gel. Second, agarose beads were prepared using paraffin sealing film. The beads were placed into microtubes, and $1 \mathrm{ml}$ of fresh sulfite solution (3.0 M sodium bisulfite, $1 \mathrm{mM}$ hydroquinone, $\mathrm{pH}$ 5.0) was added to each microtube. The samples were kept at $55^{\circ} \mathrm{C}$ in the dark in a water bath for $16 \mathrm{~h}$. The samples were then washed twice for $15 \mathrm{~min}$ each using $1 \mathrm{ml}$ wash buffer [10 mM Tris- $\mathrm{HCl}, \mathrm{pH}$ 8.0, $10 \mathrm{mM}$ ethylenediaminetetraacetate (EDTA)] and then washed 3 times for 15 min each using $1 \mathrm{ml} 10 \mathrm{~N} \mathrm{NaOH}$ solution to remove acid. The samples were then neutralized with $200 \mu \mathrm{l}$ of $1 \mathrm{~N} \mathrm{HCl} 3$ times, for $15 \mathrm{~min}$ each time. Finally, the samples were washed twice with the wash buffer. Agarose beads were cut into 4-6 equal-sized sections to be used as the methylation-specific PCR (MSP) template.

Methylation-specific PCR assay and PCR product sequencing. The primers used to detect the methylation status were synthesized according to the procedures outlined in the study by Hopkins-Donaldson et al (11). The primer sequences for caspase- 8 methylation and demethylation are listed in Table II. The sizes of the amplified products were 320 and $322 \mathrm{bp}$. PCR reaction conditions were in accordance with the methods described in the study by Hopkins-Donaldson et al (11). Known methylated DNA was used as the positive control; the negative control was the PCR reaction without a template. PCR products were separated on a $1.5 \%$ agarose gel (with ethidium bromide staining) and then photographed and analyzed under UV light. In addition, purified PCR products were ligated to the plasmid pGEMT at $4^{\circ} \mathrm{C}$ at an appropriate molecular ratio. Plasmids with high purity and quality were selected and delivered to a
Table II. Primer sequences used for RT-PCR and MSP.

Primer sequences $\left(5^{\prime} \rightarrow 3^{\prime}\right)$

$\begin{array}{ll}\text { Casp-8 } & \text { F: TCTGGAGCATCTGCTGTCTG } \\ \text { Casp-8 } & \text { R: CCTGCCTGGTGTCTGAAGTT } \\ \text { GAPDH } & \text { F: TGATGACATCAAGAA GGTGGTGAAG } \\ \text { GAPDH } & \text { R: TCCTTGGAGGCCAT GTAGGCCAT } \\ \beta \text {-actin } & \text { F: ATTGGCAATGAGCGGTTCCGC } \\ \beta \text {-actin } & \text { R: CTCCTGCTTGCTGATCCACATC } \\ \begin{array}{l}\text { Casp-8 } \\ \text { methylated }\end{array} & \text { F: TAGGGGATTCGGAGATTGCGA } \\ \begin{array}{l}\text { Casp-8 } \\ \text { methylated }\end{array} & \text { R: CGTATATCTACATTCGAAACGA } \\ \begin{array}{l}\text { Casp-8 } \\ \text { unmethylated } \\ \text { Casp-8 } \\ \text { unmethylated }\end{array} & \text { F: TAGGGGATTTGGAGATTGTGA } \\ \end{array}$

F, forward; R, reverse; GAPDH, glyceraldehyde-phosphate dehydrogenase; MSP, methylation-specific PCR.

gene sequencing company (BGI Life Technologies Co., Ltd., Beijing, China).

Caspase- 8 activity assays. Caspase- 8 activity in the HT29 and SW620 cells was assayed after the start of treatment with 5-Aza-2-deoxycytidine (5adc, $0.5 \mu \mathrm{M}$ ) for 24/48 $\mathrm{h}$ and in LN18 cells for 18/24/48 h. The cells were collected and analyzed using the Caspase- 8 Colorimetric assay kit (R\&D Systems, Minneapolis, MN, USA). The cells were lysed to collect their intracellular contents. The cell lysate was tested for protease activity by the addition of a caspase-specific peptide that was conjugated to the color reporter molecule p-nitroanaline (pNA). The cleavage of the peptide by the caspase releases the chromophore pNA, which was quantified spectrophotometrically at a wavelength of $405 \mathrm{~nm}$ using a UV spectrophotometer (BioPhotometer plus; Eppendorf Co., Ltd.). The level of caspase enzymatic activity in the cell lysate was directly proportional to the color reaction. 5-Aza-2-deoxycytidine was purchased from Sigma-Aldrich (Shangai, China).

Annexin V/propidium iodide (PI) staining and flow cytometry. The apoptotic cells were assayed after the use of camptothecin (CPT; $50 \mu \mathrm{M})$, or the combination of CPT $(50 \mu \mathrm{M})$ and 5adc $(0.5 \mu \mathrm{M})$. These agents were respectively used with the HT29, LN18 and SW620 cells for $24 \mathrm{~h}$. Apoptotic cells were assessed by Annexin V staining using the Annexin V-FITC apoptosis detection kit (BD Bioscience, Beijing, China) according to the manufacturer's instructions and analyzed by flow cytometry using CellQuest (FACSAria I; BD Biosciences, Franklin Lakes, NJ, USA). In the Annexin V assay, the cells with staining only for Annexin V-FITC (early apoptosis) were located in the lower right quadrant, whereas the cells with staining for both Annexin V and PI (late apoptosis) were located in the upper right quadrant. The percentage of positive cells for PI staining only in the top left quadrant represented 

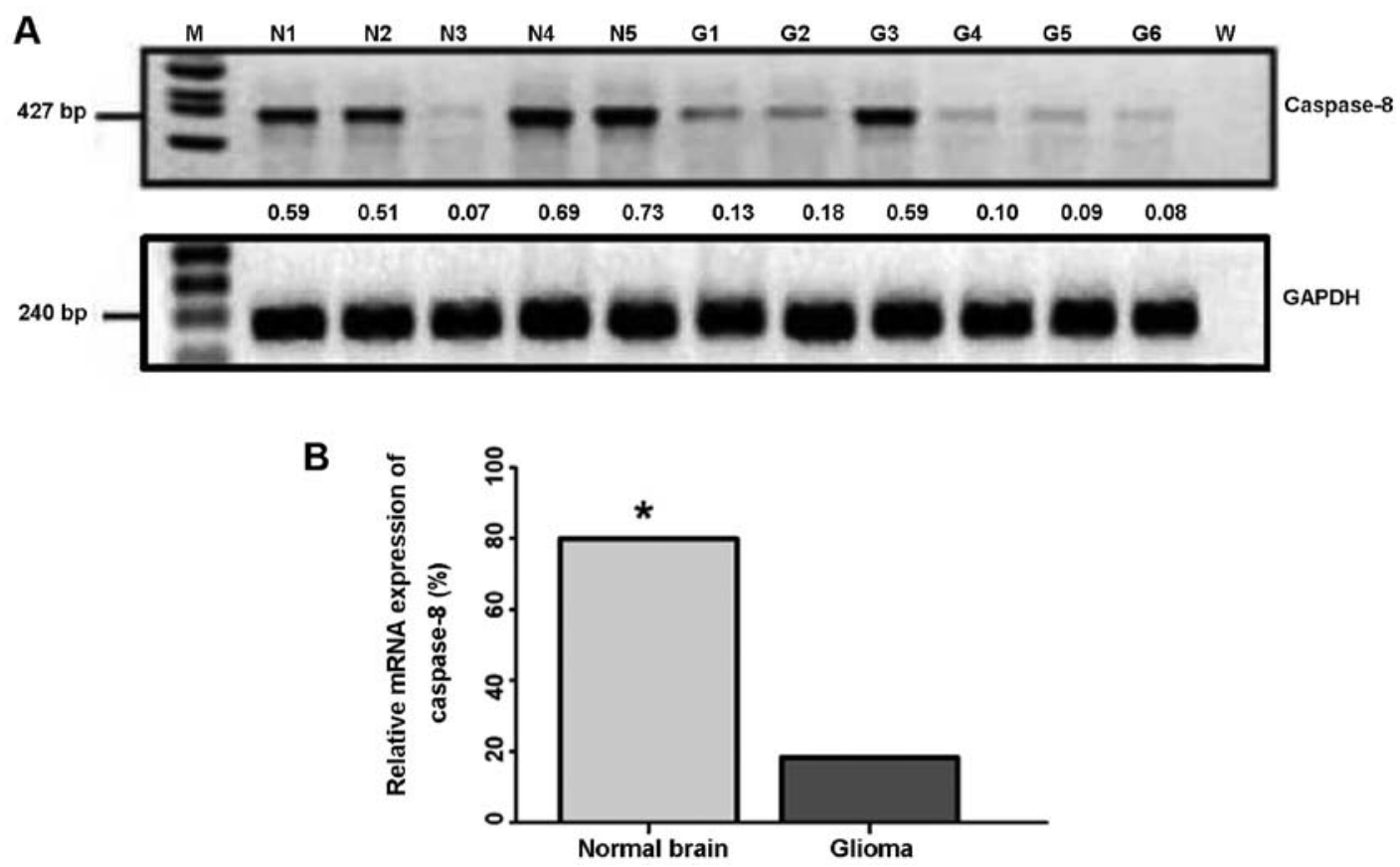

Figure 1. (A) mRNA expression of caspase-8 in normal brain tissues and glioma tissues. $\mathrm{M}$, marker; $\mathrm{N}$, normal brain tissue; $\mathrm{G}$, glioma; W, negative control. (B) The rate of the relative mRNA expression of caspase- $8(\%)$ in normal brain tissues and glioma tissues. ${ }^{*} \mathrm{P}<0.01$.

the necrotic population. CPT was purchased from SigmaAldrich.

Statistical analysis. The statistical package for social sciences (SPSS) 19.0 statistical analysis software was used. The $\chi^{2}$ test was performed on the count data, and analysis of variance (ANOVA) and the t-test were performed on the measured data. A value of $\mathrm{P}<0.05$ was considered to indicate a statistically significant difference.

\section{Results}

Downregulated mRNA expression of caspase- 8 correlates with the grade of human malignant glioma. We used RT-PCR to analyze the expression of caspase- 8 at the mRNA level in tissue of human gliomas and normal brain specimens, and semi-quantified the expression levels using the housekeeping gene, GAPDH, as the internal reference control. The results revealed that $80.0 \%$ of the normal brain tissue samples (4/5) had an intermediate to a high level of caspase- 8 expression (positive) (Fig. 1A), whereas only $18.2 \%$ of the human glioma tissue samples (12/66) had a high level of caspase-8 expression (positive) (Fig. 1A). The remaining 54 glioma tissue samples $[81.8 \%(54 / 66)]$ had very low to null levels of caspase-8 expression (negative) (Table I). Therefore, caspase-8 expression at the mRNA level in the human glioma tissues was significantly lower than that in the normal brain tissues ( $\mathrm{P}<0.01$; Fig. 1B).

To determine whether the expression of caspase- 8 is involved in the development of human glioma, we examined the association between the caspase- 8 expression level and clinicopathological indexes using the $\chi^{2}$ test. Statistical analysis revealed that the expression level of caspase- 8 was closely related to the tumor grade $(\mathrm{P}<0.05$; Table I); however, no significant correlation was observed with gender, age or tumor size $(\mathrm{P}>0.05)$.
Caspase- 8 gene silencing is a result of its gene methylation in human malignant glioma tissue. In order to investigate the mechanisms underlying the downregulation of the caspase- 8 gene in human glioma tissue, we used MSP to detect the methylation status of the caspase- 8 gene at the $\mathrm{CpG}$ island. The results indicated that, among the 66 samples, 52 samples exhibited caspase- 8 gene methylation at the $\mathrm{CpG}$ islands, as confirmed by repeated experiments. Among the 52 samples, 9 of them expressed medium to high levels of caspase- 8 at the mRNA level, whereas 43 samples expressed very low to null levels of caspase-8; yet, 25 of the 43 samples exhibited a status of high gene methylation at the $\mathrm{CpG}$ islands (Fig. 2A and B). Furthermore, statistical analysis revealed that caspase- 8 methylation was closely related to its expression at the mRNA level in human glioma tissue ( $\mathrm{P}<0.01$; Fig. 2B).

Additionally, PCR product sequencing with the MSP assay confirmed that the $\mathrm{CpG}$ islands of the caspase- 8 gene in the methylation-positive samples were indeed methylated (Fig. 2C). Moreover, among a separate set of WHO grade IV GBM patient samples that were further examined for DNA methylation (Fig. 2D) and the expression status of caspase- 8 at the mRNA level (Fig. 2E), 6 out of a total of $10 \mathrm{GBM}$ samples had gene methylation at the $\mathrm{CpG}$ islands (Fig. 2D). In addition, the mRNA expression levels of caspase-8 significantly correlated with the gene methylation status (Fig. 2D and E).

Methylation of caspase- 8 gene promoter is rare in human cancer cell lines. To verify the caspase- 8 gene methylation status in human cancer cells, we first detected the status in 6 glioma cell lines and found that only the LN18 cells had relatively low caspase- 8 gene methylation (Fig. 3A). We then examined 6 cell lines of other cancer types, including HT29 colorectal cancer cells, HeLa cervical cancer cells, K562 myelogenous leukemia cells, A431 epidermoid carcinoma cells, and DU145 and PC3 
A
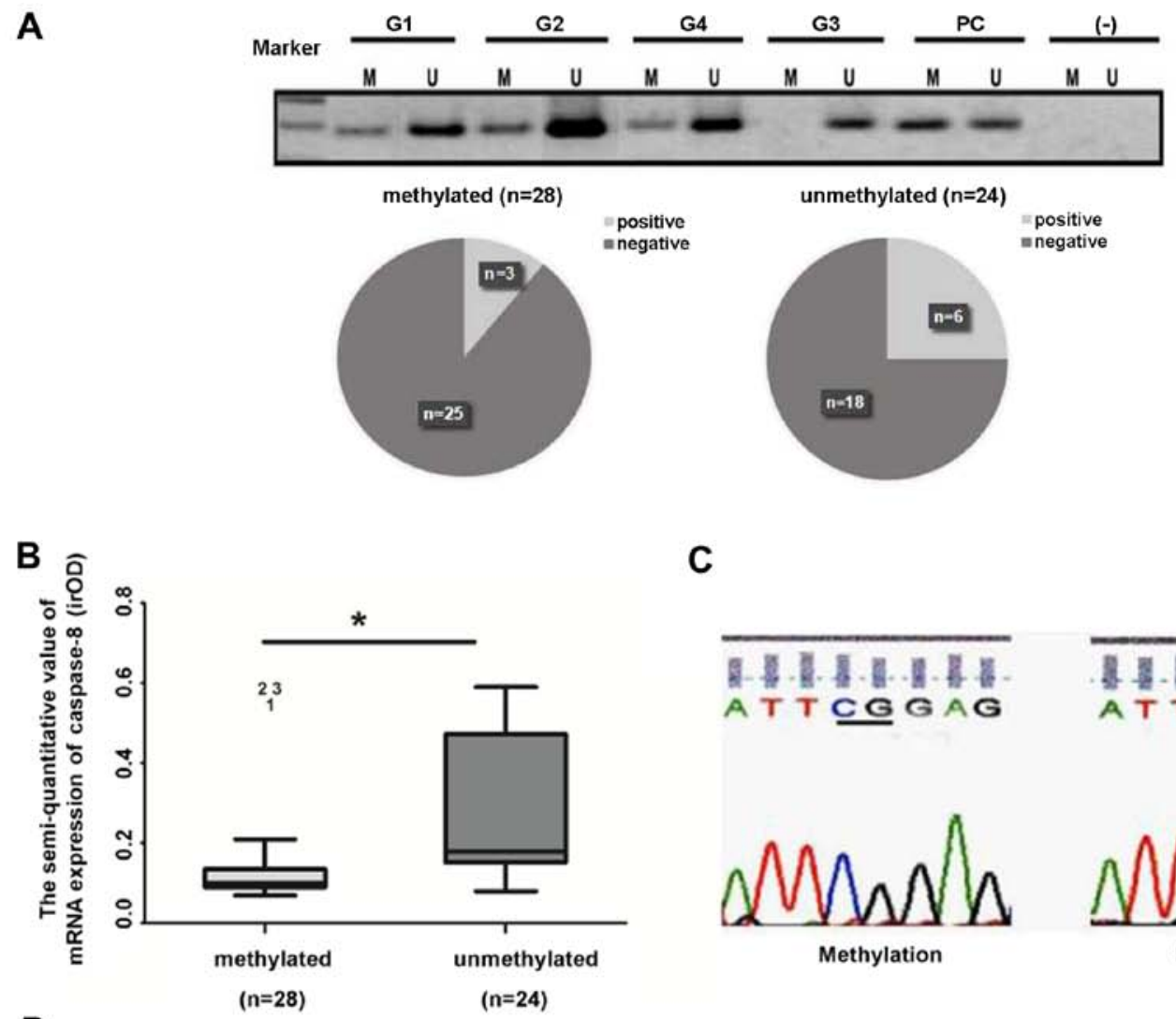

C

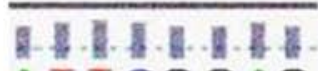

ATT CGGAG

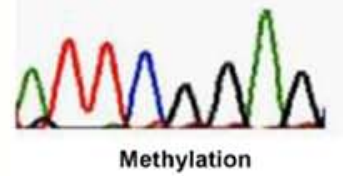

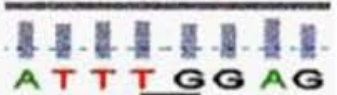

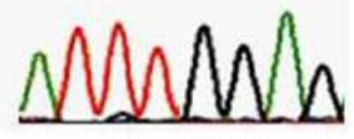

Demethylation

\section{D}

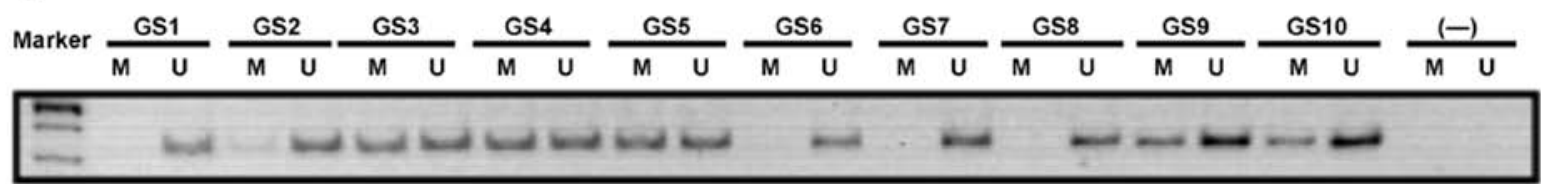

E

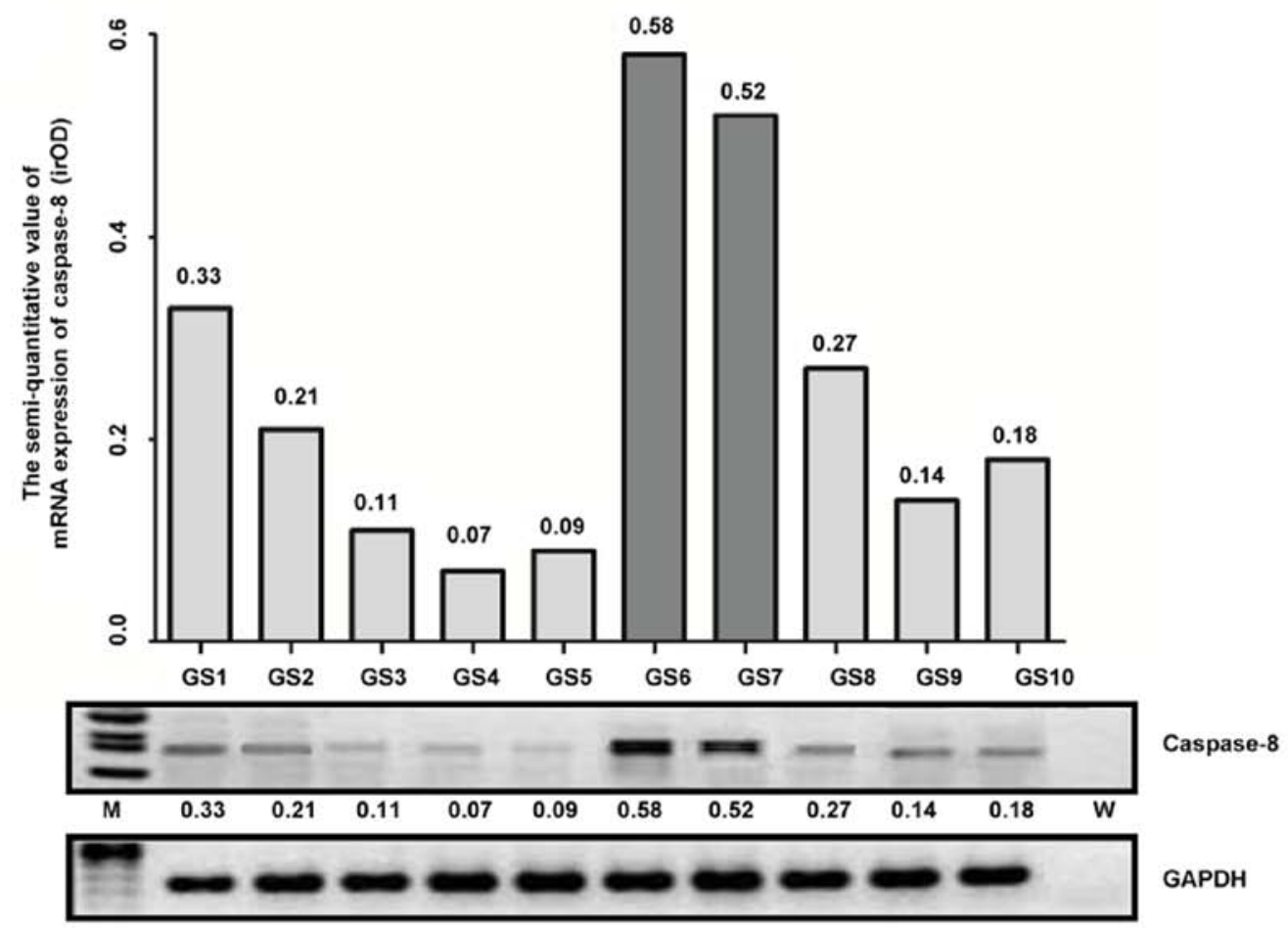

Figure 2. (A) Methylation status of caspase-8 in human glioma. Marker, DNA marker; M, methylated; U, unmethylated; G, glioma; PC, positive control; -, negative control. (B) Semi-quantitative value of mRNA expression of caspase-8 (irOD) for methylation and demethylation of caspase- 8 in glioma (t-test). "P< $<0.01$. (C) DNA sequence of caspase-8 methylation and demethylation (methylated cytosine did not change after bisulfite treatment due to the protection of the methylated group). (D) DNA methylation status. (E) Caspase-8 expression at the mRNA level in malignant glioma tissue samples from patients. GS, glioblastoma; M, methylated; U, unmethylated; -, negative control; M, marker; W, negative control. 

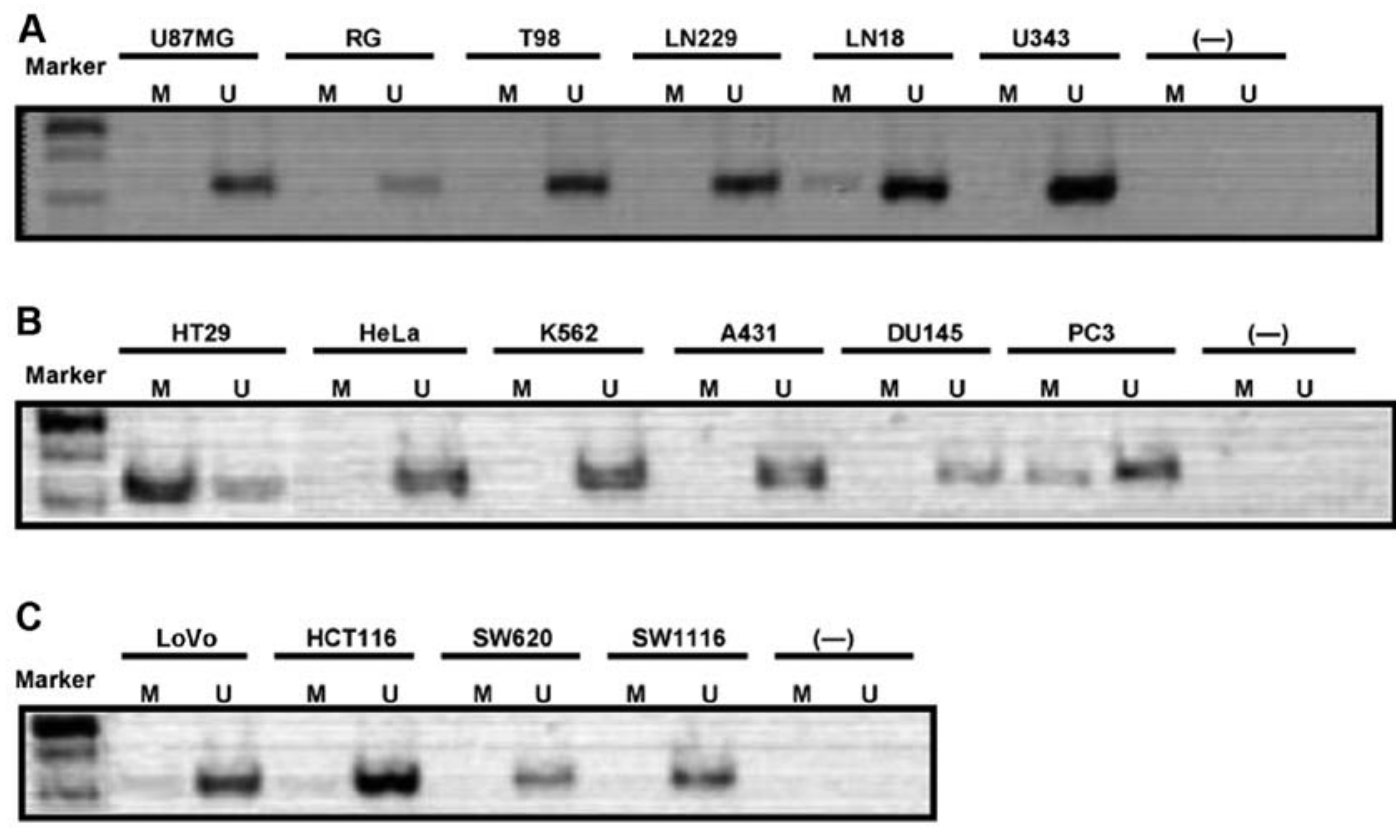

Figure 3. (A) Methylation status of caspase-8 in 6 glioblastoma (GBM) cell lines. (B) Methylation status of caspase-8 in 6 cancer cell lines. (C) Methylation status of caspase-8 in 4 other colorectal cancer cell lines. Marker, DNA marker; M, methylated; U, unmethylated; G, glioma; PC, positive control; -, negative control.

prostate cancer cell lines. The results revealed that, among these 6 cancer cell lines, only the HT29 colorectal cancer cells exhibited high caspase- 8 gene methylation at the $\mathrm{CpG}$ islands, whereas the PC3 prostate cancer cells appeared to have a relatively low methylation status. The remaining cell lines were not found to have a clear methylation (Fig. 3B). To further verify the caspase- 8 gene methylation status, we examined 4 other colorectal cancer cell lines, including LoVo, HCT116, SW620 and SW1116 cells. The data indicated that these colorectal cancer cells hardly exhibited caspase- 8 gene methylation at the CpG islands (Fig. 3C).

Anti-apoptotic activity and expression at the $m R N A$ level are highly relevant to caspase- 8 gene methylation in human cancer cells. We then used RT-PCR to analyze the expression of caspase- 8 at the mRNA level in 5 colorectal cancer cell lines and to further semi-quantify the gene expression levels using the housekeeping gene, $\beta$-actin, as the internal reference control. The results revealed that the HT29 cells, in which the caspase- 8 gene was highly methylated, exhibited a lower level of caspase- 8 expression (Fig. 4A); the other colorectal cancer cell lines exhibited a higher level of caspase- 8 expression, but relatively low gene methylation, as compared to the HT29 cells (Figs. 3B and C and 4A).

We further verified whether caspase- 8 protein kinase activity was highly relevant to its gene methylation status by treating the tumor cells with 5adc, a demethylation reagent. The data indicated that treatment with 5adc restored caspase- 8 protein kinase activity in the HT29 and LN18 cells, but not in the SW620 cells. In the HT29 cells, the expression of caspase- 8 was upregulated at both 24 and $48 \mathrm{~h}(\mathrm{P}<0.05$; Fig. 4B, panel a); in the LN18 cell, the upregulation occurred only at $24 \mathrm{~h}(\mathrm{P}<0.05$; Fig. $4 \mathrm{~B}$, panel b); however, in the SW620 cells, caspase- 8 activity was not restored (Fig. 4B, panel c) following treatment with 5adc.
To confirm the function of the upregulated caspase- 8 protein activity by treatment with a demethylation agent, we assayed the apoptotic cells in the HT29, LN18 and SW620 cell lines following treatment with CPT (50 $\mu \mathrm{M})$ alone, or in combination with $5 \operatorname{adc}(0.5 \mu \mathrm{M})$ for $24 \mathrm{~h}$. The apoptosis assay carried out by flow cytometry revealed that the HT29 cell apoptotic rate in the combination group was $79.3 \pm 8.07 \%$, which was significantly higher than that in the group treated with CPT alone $(18.67 \pm 3.52 \%$; $<<0.05$; Fig. $4 \mathrm{C}$, panel a). These values $(79.3 \pm 8.07 \%$ and $18.67 \pm 3.52 \%)$ are presented as mean values of at least 3 experiments. In Fig. $4 \mathrm{C}$, the values are presented as the percentage of one experiment. However, no difference was observed as regards the apoptotic rate of the LN18 and SW620 cells between CPT treatment alone and the combination therapy $(\mathrm{P}>0.05$; Fig. $4 \mathrm{C}$, panels $\mathrm{b}$ and $\mathrm{c}$ ).

\section{Discussion}

It has been demonstrated that caspase- 8 is frequently lost or silenced in human GBM (13) and a variety of human cancers (23-25). In this study, we demonstrated that the majority of our tested brain glioma samples exhibited a decreased or null caspase-8 mRNA expression; the tumor samples exhibited a significantly decreased caspase- 8 expression as compared to the normal brain tissue samples. Furthermore, we demonstrated that caspase- 8 expression at the mRNA level was significantly downregulated in 39 out of 43 cases of high grade glioma (WHO III-IV). In fact, a significantly decreased expression of caspase- 8 was closely associated with a higher tumor grade in human glioma tissues, as previously demonstrated (26). Our data suggest that the downregulated caspase- 8 expression may be involved in human glioma development and progression. 
A
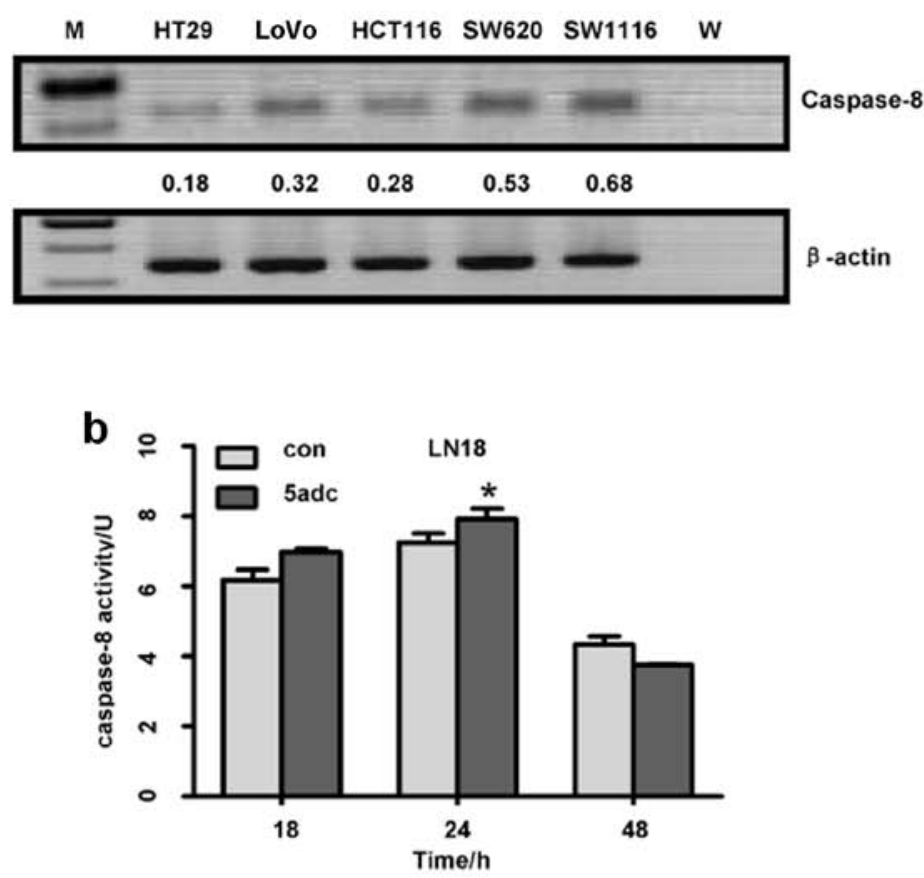

B

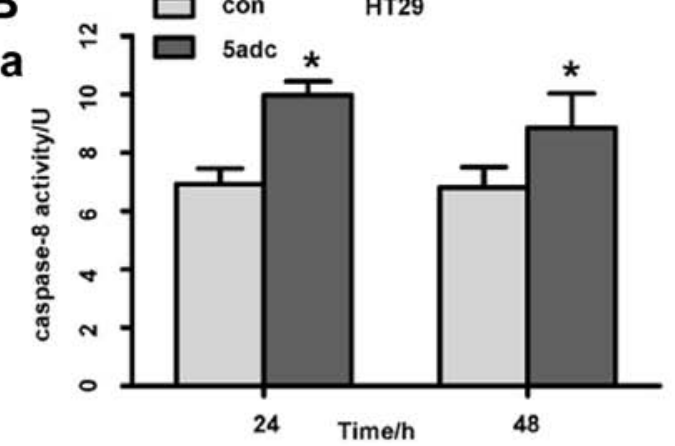

C

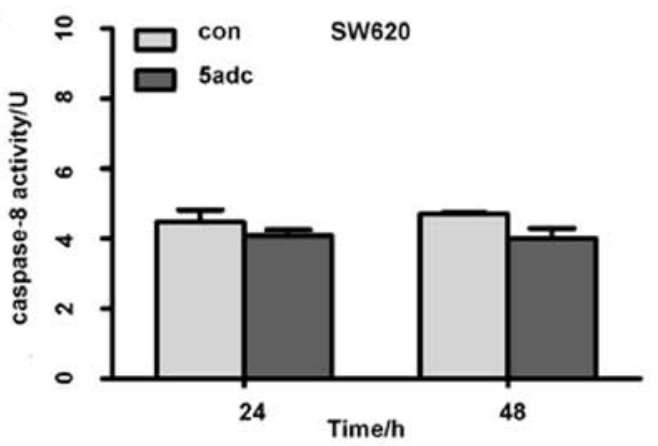

C
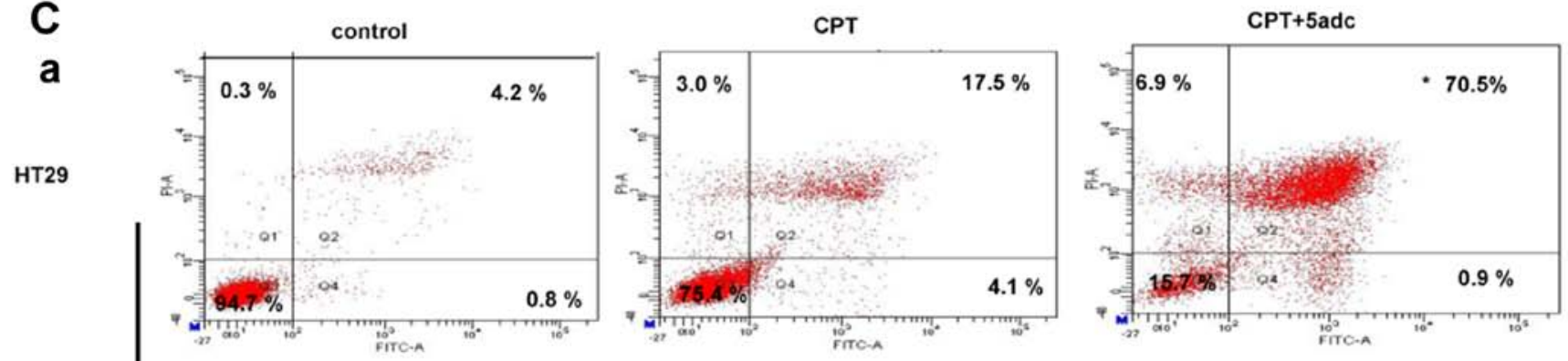

b

LN18

N18
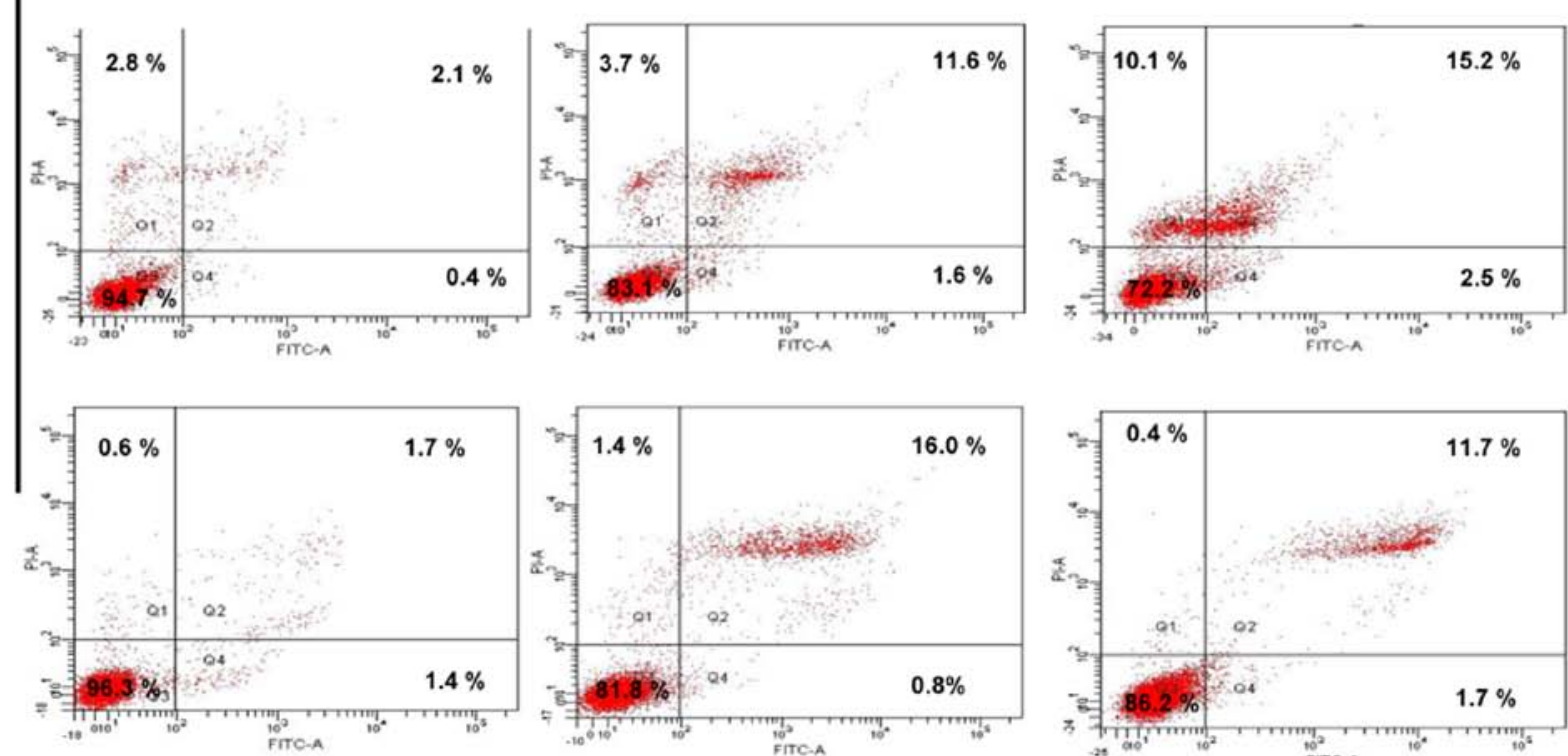

C
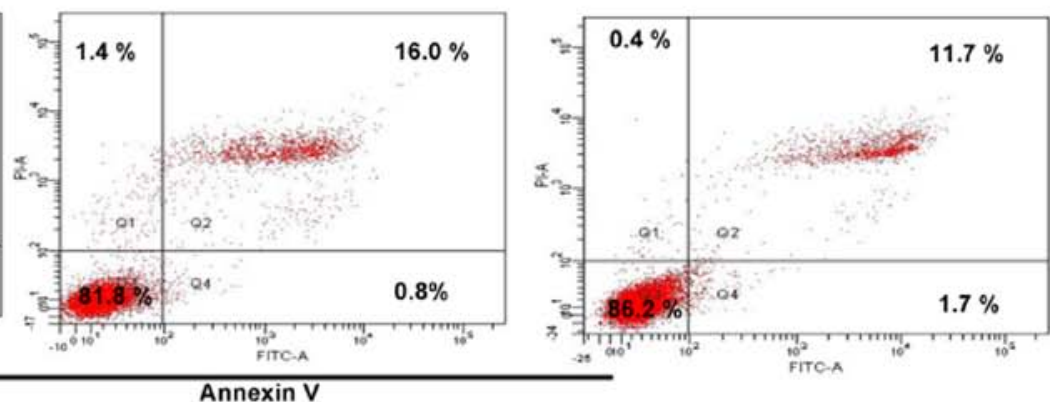

Figure 4. (A) mRNA expression of caspase- 8 in 5 colorectal cell lines. M, marker; W, negative control. (B) Caspase-8 activity in HT29 and SW620 cells upon treatment with 5-Aza-2-deoxycytidine (5adc) $(0.5 \mu \mathrm{M})$ for $24 / 48 \mathrm{~h}$ and in LN18 cells for 18/24/48 h. The control is untreated cells. Experiments were performed at least 3 times. "P<0.05 indicates values that are different from the respective control (ANOVA). Panel a, HT29 cells; panel b, LN18 cells; panel c, SW620 cells. (C) Apoptotic cell assay in HT29, LN18 and SW620 cells upon treatment with CPT $(50 \mu \mathrm{M})$ and the combination of CPT (50 $\mu \mathrm{M})$ and $5 \mathrm{adc}(0.5 \mu \mathrm{M})$ for $24 \mathrm{~h}$. The control is untreated cells. Experiments were performed at least 3 times. ${ }^{*} \mathrm{P}<0.05$ indicates values that are different from the respective control (ANOVA). Panel a, HT29 cells; panel b, LN18 cells; panel c, in SW620 cells. 
The mechanisms underlying the loss of gene expression, include the loss of heterozygosity $(\mathrm{LOH})$, point mutation and $\mathrm{CpG}$ island methylation. Of these, $\mathrm{CpG}$ island methylation plays a key role in the regulation of gene expression in a variety of disease-related factors, including apoptotic effectors (27). Previous human glioma studies have indicated that gene mutation in caspase- 8 occurs infrequently (28); no LOH in glioma has been reported thus far. In our results, caspase- 8 gene promoter methylation analysis in glioma tissue specimens revealed that within the 43 cases of caspase- 8 mRNA negative expression, $58.1 \%$ had a high methylation. Our data are in accordance with those of other related studies, which indicated that $\mathrm{CpG}$ island abnormal methylation contributed to the downregulation on the transcriptional activity of the caspase- 8 gene (13,23-25). Thus far, however, the mechanisms that are involved in the development and progression of human glioma are not fully understood and appear highly complex. There may be other factors that contribute to caspase- 8 downregulation or gene damage, leading to an anti-apoptotic effect in tumors, e.g., LOH $(29,30)$.

To our surprise, whereas we tried to elucidate the mechanisms of caspase- 8 gene methylation and downregulated expression in vitro with malignant glioma cells, we did not observe the same phenomena as those in human glima tissue. Only 1 of the 6 tested malignant glioma cells, the LN18 cells, had a minor methylation at the caspase- 8 gene promoter. Such a lack of caspase- 8 gene methylation was further observed in 10 other immortal cell lines of other cancer types, including 5 colorectal cancer cell lines and 5 cell lines of other cancer types, among which we only found that the HT29 colorectal cancer cells had a high level of caspase- 8 gene methylation. These data indicate that there may be a significant difference in anti-apoptotic properties between immortal tumor cell lines in vitro and tumor cells in vivo. For example, the tumor cell lines in vitro may adapt different routes of anti-apoptotic features as the tumor microenvironment in vivo may be an essential element for tumor development and progression in vivo $(31,32)$. Further investigations are warranted to confirm whether our in vitro model used to elucidate the mechanisms and aid in the development novel treatment strategies for cancer patients was reliable.

Nevertheless, taking advantage of a varied caspase- 8 methlytion status in the HT29 colorectal cancer cells, the LN18 malignant glioma cells and the SW620 colorectal cancer cells, in which caspase- 8 had a respectively high, low or null level of methylation, we confirmed that a high level of caspase- 8 gene methylation was significantly associated with its gene downregulation, reduced kinase activity and increased anti-apoptotic properties in tumor cells. Therefore, we indirectly verified that an increased caspase- 8 gene methylation may be highly relevant to the development and progression of human malignant glioma in vivo. However, the limitations of this study may be as follows: i) the number of glioma tissue samples was relatively small; ii) we provide indirect evidence that a high methylation status of caspase- 8 is closely associated with anti-apoptotic mechanisms in human glioma; iii) the occurrence and development of human glioma is complex and involves multi-gene and functional pathways. Thus, further studies are warranted to confirm our findings and to further determine the mechanisms responsible for glioma malignancy.

\section{Acknowledgements}

The present study was supported by grants from the Natural Science Foundation of China (nos. 91229112, 30772238 and 81472367 to H.R. and 81402054 to Y.-C.D.), the Heilongjiang Province and China Postdoctoral Projects (nos. LBH-Z14138, 2014M560272 and 2015T80371 to Y.-C.D.); the Natural Science Foundation of Heilongjiang Province (no.s414002989-15057 to Y.-C.D.).

\section{References}

1. Fuller GN and Scheithauer BW: Symposium: The 2007 revised world health organization (WHO) Classification of tumors of the central nervous system: newly codified entities. Brain Pathol 17: 304-307, 2007.

2. Thompson CB: Apoptosis in the pathogenesis and treatment of disease. Science 267: 1456-1462, 1995.

3. Varela M, Ranuncolo SM, Morand A, Lastiri J, De Kier Joffé EB, Puricelli LI and Pallotta MG: EGF-R and PDGF-R, but not bcl-2, overexpression predict overall survival in patients with low-grade astrocytomas. J Surg Oncol 86: 34-40, 2004.

4. Kajiwara Y, Yamasaki F, Hama S, Yahara K, Yoshioka H, Sugiyama K, Arita K and Kurisu K: Expression of survivin in astrocytic tumors: Correlation with malignant grade and prognosis. Cancer 97: 1077-1083, 2003.

5. Sarkar C, Karak AK, Nath N, Sharma MC, Mahapatra AK, Chattopadhyay P and Sinha S: Apoptosis and proliferation: Correlation with p53 in astrocytic tumours. J Neurooncol 73: 93-100, 2005.

6. Grenet J, Teitz T, Wei T, Valentine V and Kidd VJ: Structure and chromosome localization of the human CASP8 gene. Gene 226: 225-232, 1999.

7. Boldin MP, Goncharov TM, Goltsev YV and Wallach D: Involvement of MACH, a novel MORT1/FADD-interacting protease, in Fas/APO-1- and TNF receptor-induced cell death. Cell 85: 803-815, 1996.

8. Muzio M, Chinnaiyan AM, Kischkel FC, O'Rourke K, Shevchenko A, Ni J, Scaffidi C, Bretz JD, Zhang M, Gentz R, et al: FLICE, a novel FADD-homologous ICE/CED-3-like protease, is recruited to the CD95 (Fas/APO-1) death--inducing signaling complex. Cell 85: 817-827, 1996.

9. Deng Y, Lin Y and Wu X: TRAIL-induced apoptosis requires Bax-dependent mitochondrial release of Smac/DIABLO. Genes Dev 16: 33-45, 2002.

10. Blanchard H, Donepudi M, Tschopp M, Kodandapani L, Wu JC and Grütter MG: Caspase- 8 specificity probed at subsite $S(4)$ : Crystal structure of the caspase-8-Z-DEVD-cho complex. J Mol Biol 302: 9-16, 2000.

11. Hopkins-Donaldson S, Ziegler A, Kurtz S, Bigosch C, Kandioler D, Ludwig C, Zangemeister-Wittke U and Stahel R: Silencing of death receptor and caspase-8 expression in small cell lung carcinoma cell lines and tumors by DNA methylation. Cell Death Differ 10: 356-364, 2003.

12. McKee AE and Thiele CJ: Targeting caspase 8 to reduce the formation of metastases in neuroblastoma. Expert Opin Ther Targets 10: 703-708, 2006.

13. Ashley DM, Riffkin CD, Muscat AM, Knight MJ, Kaye AH, Novak U and Hawkins CJ: Caspase 8 is absent or low in many ex vivo gliomas. Cancer 104: 1487-1496, 2005.

14. Jones PA: DNA methylation and cancer. Oncogene 21: 5358-5360, 2002.

15. Galm O, Wilop S, Reichelt J, Jost E, Gehbauer G, Herman JG and Osieka R: DNA methylation changes in multiple myeloma. Leukemia 18: 1687-1692, 2004.

16. Sun T, Gao Y, Tan W, Ma S, Shi Y, Yao J, Guo Y, Yang M, Zhang X, Zhang Q, et al: A six-nucleotide insertion-deletion polymorphism in the CASP8 promoter is associated with susceptibility to multiple cancers. Nat Genet 39: 605-613, 2007.

17. Shen L, Kondo Y, Rosner GL, Xiao L, Hernandez NS, Vilaythong J, Houlihan PS, Krouse RS, Prasad AR, Einspahr JG, et al: MGMT promoter methylation and field defect in sporadic colorectal cancer. J Natl Cancer Inst 97: 1330-1338, 2005.

18. Shen DH, Chan KY, Khoo US, Ngan HY, Xue WC, Chiu PM, Ip P and Cheung AN: Epigenetic and genetic alterations of p33 $3^{\mathrm{ING16}}$ in ovarian cancer. Carcinogenesis 26: 855-863, 2005. 
19. Kim JH, Choi YD, Lee JS, Lee JH, Nam JH and Choi C: Assessment of DNA methylation for the detection of cervical neoplasia in liquid-based cytology specimens. Gynecol Oncol 116: 99-104, 2010

20. Hildebrandt MA, Gu J, Lin J, Ye Y, Tan W, Tamboli P, Wood CG and $\mathrm{Wu} \mathrm{X}$ : Hsa-miR-9 methylation status is associated with cancer development and metastatic recurrence in patients with clear cell renal cell carcinoma. Oncogene 29 : 5724-5728, 2010

21. Park SY, Kook MC, Kim YW, Cho NY, Jung N, Kwon HJ, Kim TY and Kang GH: CpG island hypermethylator phenotype in gastric carcinoma and its clinicopathological features Virchows Arch 457: 415-422, 2010.

22. Kitazawa S, Kitazawa R and Maeda S: Identification of methylated cytosine from archival formalin-fixed paraffin-embedded specimens. Lab Invest 80: 275-276, 2000.

23. Hopkins-Donaldson S, Bodmer JL, Bourloud KB, Brognara CB Tschopp J and Gross N: Loss of caspase-8 expression in highly malignant human neuroblastoma cells correlates with resistance to tumor necrosis factor-related apoptosis-inducing ligandinduced apoptosis. Cancer Res 60: 4315-4319, 2000.

24. Hopkins-Donaldson S, Bodmer JL, Bourloud KB, Brognara CB, Tschopp J and Gross N: Loss of caspase-8 expression in neuroblastoma is related to malignancy and resistance to TRAIL-induced apoptosis. Med Pediatr Oncol 35: 608-611, 2000.

25. Teitz T, Wei T, Valentine MB, Vanin EF, Grenet J, Valentine VA Behm FG, Look AT, Lahti JM and Kidd VJ: Caspase 8 is deleted or silenced preferentially in childhood neuroblastomas with amplification of MYCN. Nat Med 6: 529-535, 2000.
26. Saggioro FP, Neder L, Stávale JN, Paixão-Becker AN, Malheiros SM, Soares FA, Pittella JE, Matias CC, Colli BO, Carlotti CG Jr, et al: Fas, FasL, and cleaved caspases 8 and 3 in glioblastomas: A tissue microarray-based study. Pathol Res Pract 210: 267-273, 2014.

27. Jones PA and Baylin SB: The fundamental role of epigenetic events in cancer. Nat Rev Genet 3: 415-428, 2002.

28. Gonzalez-Gomez P, Bello MJ, Inda MM, Alonso ME, Arjona D, Amiñoso C, Lopez-Marin I, de Campos JM, Sarasa JL, Castresana JS, et al: Deletion and aberrant $\mathrm{CpG}$ island methylation of caspase-8 gene in medulloblastoma. Oncol Rep 12: 663-666, 2004.

29. Knudson AG Jr: Mutation and cancer: Statistical study of retinoblastoma. Proc Natl Acad Sci USA 68: 820-823, 1971.

30. Ebinger M, Senf L, Wachowski O and Scheurlen W: Promoter methylation pattern of caspase-8, P16 ${ }^{\mathrm{INK} 4 \mathrm{~A}}, \mathrm{MGMT}$, TIMP-3, and E-cadherin in medulloblastoma. Pathol Oncol Res 10: 17-21, 2004.

31. Adams DJ, Waud WR, Wani MC, Manikumar G, Flowers JL, Driscoll TA and Morgan LR: BACPTDP: A water-soluble camptothecin pro-drug with enhanced activity in hypoxic/acidic tumors. Cancer Chemother Pharmacol 67: 855-865, 2011.

32. Xia S, Lal B, Tung B, Wang S, Goodwin CR and Laterra J: Tumor microenvironment tenascin-C promotes glioblastoma invasion and negatively regulates tumor proliferation. Neuro Oncol 18: 507-517, 2016. 